\title{
BEHAVIORAL CONTRACTING WITH DELINQUENTS: A CAUTIONARY NOTE*
}

\author{
RICHARD B. STUART $\dagger$ \\ University of Michigan and Behavior Change Laboratories \\ and \\ LEROY A. LOTT $\mathbf{J}_{\mathbf{R}}$. \\ Behavior Change Laboratories
}

\begin{abstract}
Summary-Seventy-nine predelinquent and delinquent youths and their families were offered treatment utilizing contingency contracting as an element of time-constrained $(15,45$, or 90-day) treatment. An analysis of contracts and their effects yielded the following conclusions: (a) contracts tend to depend more upon the therapist and his interventions than upon features of the client; (b) the characteristics of contracts appear unrelated to treatment outcome. The first conclusion implies a need to structure treatment so as to reduce the impact of individual therapist characteristics. The second conclusion implies that other factors, either in the treatment (such as the facilitation of communication) or in the techniques of service delivery (such as the process of negotiating behavioral contracts) are the real determinants of treatment outcome.
\end{abstract}

EVER since Patterson and his associates coined the notion of "reprogramming the social environment (Patterson et al., 1967)" in order to bring family forces to bear upon the problems of delinquent behavior, considerable effort has gone into youth services aimed at utilizing the resources available in home and school environments to enhance the probability of prosocial behavior (Patterson, 1971; Stuart, 1971b). Tharp and Wetzel (1969) conceived of this process as building upon the efforts of therapists to modify the behavior of mediators--typically parents, other family members and/or teacherswho in turn are expected to exert positive behavioral control over the adolescent. Beyond a mere instrument at the service of the therapists, however, the mediator is himself the intermediate target of a process of behavior change "which requires that we view every member of the system as equally needful of a new homeostasis (Tharp, 1971, p. 5)." In accord with this approach, then, services to youth must be viewed as efforts to modify not only the behavior of the youngster but also the actions of those adults who significantly influence his actions. In contrast to the more familiar individually focused efforts to directly change the behavior of the predelinquent or delinquent, this approach entails microsocial engineering in the fullest possible sense (Stuart, in press).

Beginning with identification of the family rather than the youth as a target of change efforts, the role of family interaction as pathogenic or hygienic becomes a central issue. Under normal circumstances, well-functioning familial interaction involves predictable, norm-governed exchanges (Thibaut and Kelley, 1959) which sustain a process of mutual influence or mutual

* Paper presented at the University of Missouri, Columbia, Missouri, 21 October 1971. This research has been funded through a grant from the Center for the Study of Crime and Delinquency of the National Institute of Mental Health. The authors wish to express their gratitude to the staff of the Family and School Consultation Project for carrying out the intervention, to Mr. Siri Jayaratne for his assistance with the data analysis, to Miss Jan Onder for her work on the early stages of formulation, and to Miss Lynn Nilles for her editorial assistance. tRequests for reprints should be submitted to Richard B. Stuart, School of Social Work, The University of Michigan, 1065 Frieze Building, Ann Arbor, Michigan 48104. 
contingency control (Jones and Gerard, 1967, p. 507). The norms which are intercurrent with effective social behavior within families are often followed in a completely reliable fashion by all family members despite their having never been explicated (Carson, 1969, p. 184). When dysfunctional interactions occur, however, it is not uncommon for an aggrieved family member to seek to re-establish a favorable equity in the interaction through explication of the norms in the form of relationship rules. The intent of rule statement is the repair of patterns characterized by Patterson and Reid (1970) as "coercive" insofar as they are characterized by the use of negative reinforcement which would lead to a "reciprocal" relationship. When rules are stated and accepted, the result is an implied behavioral contract which might remain in effect for a single encounter or for the entire relationship.

Observations of intrafamilial interaction involving delinquents and their parents suggest that often neither implicit norms nor explicated rules are sufficient to establish reciprocal interaction. As a result, authors such as Tharp and Wetzel (1969) have suggested the use of explicit behavioral contracts as a means of facilitating the predictable exchange of reinforcers within families. When successfully negotiated, contracts may not only change serious conflict to positive social interaction, but they may also provide the family with training in a style of conflict resolution which can have long-range benefits.

In an effort to validate the usefulness of behavioral contracts in services to youth, along with efforts to ascertain other minimally necessary attributes of those services, the Family and School Consultation Project has completed the first of $4 \mathrm{yr}$ of research (Stuart and Tripodi, in press). During this first, pre-test year, 94 junior high school predelinquents and delinquents were referred for service. Of these, 79 families completed an initial therapeutic interview and were assigned at random to either 15,45 , or 90 -day time-limited treatment. The 15 families declining an initial therapeutic contact were designated as a "comparison" group. Regardless of time constraint, all interventions had in common the initiation of a behavioral contract during the first therapeutic session and an early contract with at least two of the adolescent's teachers. Wherever possible, other aspects of the intervention were standardized. For example, videotape demonstrations were offered to therapists throughout the year in an effort to train each in maximizing the use of positive influence techniques and minimizing that of negative confrontation. In addition, audio-tapes of interviews were spot checked at different times during the year in an effort to identify problems faced by therapists in fulfilling the research requirement of highly structured interviews.

The effectiveness of the intervention was determined through the use of 10 measures falling into four major categories. To assess behavior in school, grades, attendance, tardiness and social behavior in the classroom were determined by teacher ratings using the Pupil Behavior Inventory (Vinter et al., 1966). To assess behavior at home, a Parent Evaluation Form was completed by one or two parents with whom the adolescent resided, while behavior in the community was assessed through reference to juvenile court records. Finally, changes in the attitudes of the adolescent were assessed through use of the Jesness Social Maladjustment Scale (Jesness, 1963) while changes in parental attitudes were assessed using a specially constructed Pretreatment Questionnaire. The selection of these measures, however, does not satisfactorily solve the problem of criterion selection in research of this sort. For example, Sarri and Vinter (1969) have shown that grades are eminently unresponsive to changes in the behavior of treated adolescents whose achievement test scores and social behavior in school might improve markedly. Meanwhile, with respect to another parameter, attitude change may be unrelated to behavioral change.

\section{TYPICAL CONTRACT CONTENTS}

Even with less than optimal specification of dependent variables, it is reasonable to explore 
the role of behavioral contracts in the experimental intervention. The general form of contracts used in this research is described elsewhere (Stuart, 1971a). Essentially the contracts contain statements of privileges (reinforcements) and responsibilities (responses) for the adolescent, with the understanding that the privileges and responsibilities of the parents are the reciprocals of those of the youth. Moreover many contracts contain provisions for sanctions to prestructure parents' responses to contract violations, bonuses to maintain parental tracking of the youth's contract compliance, and monitoring forms to assess more easily all contractrelevant behaviors by all parties to the contract.

A description of the content of typical contracts negotiated during the first therapeutic session is contained in Table 1 . Here it can be seen that the average first contract contained approximately 12 items overall and almost one third more responsibilities than privileges. Within each of these average categories, however, data were distributed rectalinearly. For example, on the first contract 23.0 per cent of the families had either one or two privileges, 29.7 per cent had three or four, 27 per cent had five or six and 20.3 per cent had seven or more. This distribution is in keeping with the process of contract negotiation which presumably encouraged each family to individualize its own contract.

Only one half of the families had a single contract during the course of treatment; $32 \cdot 4$ per cent renegotiated their contract one time. 12.1 per cent two or three times, and 5.5 per cent four or more times. A contract was considered to be renegotiated only when substantial changes were made, with minor implementing additions being considered as techniques of contract facilitation. A major change would be the addition of new privileges or responsibilities, while a minor change would be the introduction of the parent in place of a school counselor as a monitor for homework.

As can be seen from Table 1, the second contracts tend to be quite similar to the first. Subsequent contracts, however, tended to be longer than their precursors, with privileges, responsibilities, bonuses and sanctions increasing from an average of $4.25,5.35,1.40$ and 1.05 respectively for the first two contracts to an average of $5 \cdot 85,6 \cdot 65,2 \cdot 15$, and $2 \cdot 70$ respectively for the final contracts.

\section{CONTRACT PROVISIONS FOR FAMILIES OF VARYING CHARACTERISTICS}

Within the general rubric of structured bargaining, the distribution of the provisions of

Table 1. Average nUmber of provisions of Contracts With the FAMILIES OF PREDELINQUENT AND DELINQUENT JUNIOR HIGH SCHOOL STUDENTS

\begin{tabular}{ccccc}
\hline & $\begin{array}{c}\text { First } \\
\text { contract }\end{array}$ & $\begin{array}{c}\text { Second } \\
\text { contract }\end{array}$ & $\begin{array}{c}\text { Third and } \\
\text { fourth } \\
\text { contracts }\end{array}$ & $\begin{array}{c}\text { Fifth and } \\
\text { later } \\
\text { contracts }\end{array}$ \\
\hline & $(N=47)$ & $(N=24)$ & $(N=10)$ & $(N=6)$ \\
\hline $\begin{array}{c}\text { Privileges } \\
\text { Average }\end{array}$ & $4 \cdot 2$ & $4 \cdot 3$ & $5 \cdot 5$ & $6 \cdot 2$ \\
$\begin{array}{c}\text { Range } \\
\text { Responsibilities } \\
\text { Average }\end{array}$ & $1-10$ & $2-13$ & $2-9$ & $5-10$ \\
$\begin{array}{c}\text { Range } \\
\text { Bonuses } \\
\text { Average }\end{array}$ & $5 \cdot 4$ & $5 \cdot 3$ & $6 \cdot 1$ & $7 \cdot 0$ \\
$\begin{array}{c}\text { Range } \\
\text { Sanctions } \\
\text { Average }\end{array}$ & $1-16$ & $2-13$ & $4-9$ & $4-11$ \\
$\begin{array}{c}\text { Range } \\
\text { Total items } \\
\text { Average }\end{array}$ & $1 \cdot 4$ & $1 \cdot 4$ & $1 \cdot 7$ & $2 \cdot 5$ \\
Range & $0-3$ & $0-5$ & $0-3$ & $1-5$ \\
\hline
\end{tabular}


contracts will naturally vary as a function of the differing objectives and expectations of adolescents and parents of different characteristics. This accords with the process by which the staff generated contracts, a process in which each member of the family was asked to sort cards referring to the privileges which he desired before negotiating an exchange of privileges with other family members. To assess the variability in contract contents across client groups chisquare analyses were carried out comparing the following client characteristics with the following contract contents: clients revealed that treatment outcome was apparently unrelated to assigning a client one of three time-constrained intervention conditions, although the clients assigned to experimental groups outperformed those in a contrast condition. As the length of treatment did not explain the outcome variance in the earlier analysis, we may suppose that the specifics of the behavioral contracts ranging from 2 to 30 items formulated with each family might be predictive of therapeutic outcome. Either the contracts might reflect differential initial readiness of families to negotiate their differences or

\begin{tabular}{|c|c|}
\hline Client characteristics & Contract content \\
\hline $\begin{array}{l}\text { Grade }(7,8,9) \\
\text { Sex } \\
\text { Race } \\
\text { Parents' education (some vs } \\
\text { no college) } \\
\text { Single vs both parent families } \\
\text { Family income (below } \$ 9,999 \text { vs } \\
\text { above } \$ 10,000 \text { ) }\end{array}$ & $\begin{array}{l}\text { Overall length of contract } \\
\text { Number of privileges } \\
\text { Number of responsibilities } \\
\text { Number of bonuses } \\
\text { Number of sanctions } \\
\text { Balance of privileges and bonuses } \\
\text { vs responsibilities and sanctions } \\
\text { Inclusion of school attendance or } \\
\text { school performance responsibilities } \\
\text { Inclusion of home chore responsibilities } \\
\text { Inclusion of money or free time privileges } \\
\text { Number of contract revisions }\end{array}$ \\
\hline
\end{tabular}

Of the 80 resulting comparisons, only three attained statistical significance. These reflected the facts that the contracts of ninth-grade students tended to have more sanctions than those of seventh-grade students; that the ninth graders throughout tended to have more negatively balanced contracts (responsibilities and sanctions vs privileges and bonuses) than seventh graders; and that the contracts of the ninth graders were more likely to undergo revision than those of the seventh graders. At least four comparisons would have yielded significant differences by chance alone; therefore we may conclude that the characteristics of client families do not exert a salient influence upon the content of family contracts.

\section{CONTRACT PROVISIONS RELATED TO OUTCOME}

An earlier paper by Stuart and Tripodi (in press) which utilized the data from these same they might reflect a change within famılies where members are willing to accommodate to the requests of each other, both presumably influencing the outcome of service.

Bearing in mind that some outcome measures are more revealing than others, changes on the 10 criteria were evaluated with respect to each of the following attributes of contracts:

Overall length of contract,

Number of privileges,

Number of bonuses,

Number of sanctions,

Number of times contracts were renegotiated,

Inclusion of school attendance and/or performance responsibilities,

Inclusion of home chore responsibilities,

Inclusion of money and/or free time privileges.

Of the resulting 100 chi-square comparisons, only six achieved a level of significance, a finding which could well have occurred by chance. 
Significant results were obtained in the following areas: (a) for those clients whose contracts included the use of class cards (Stuart, 1971a, p. 6), attendance improved significantly although tardiness, grades and social behavior in the classroom made no such change when the cards were used; (b) parental attitudinal agreement increased if contracts contained school performance responsibilities or money privileges and also if contracts were longer than average, although parental disagreement was not initially associated with the length of contracts; and (c) when contracts were positively balanced, with the number of privileges and bonuses exceeding the number of responsibilities and sanctions, attendance at school was likely to increase sharply. Regrettably there is no clear rationale for any of these trends, all three of which conform to a priori expectation.

\section{INTERACTION BETWEEN EXPECTED DURATION OF TREATMENT AND CONTRACT CONTENTS}

In an experiment in which both therapists and clients are aware of the fact that the intervention is arbitrarily (through random assignment) timelimited, one would expect family contracts to fluctuate somewhat as a function of the expected duration of treatment. For example, therapists and clients working within a time limit as short as 15 days might be expected to attempt to achieve more change initially than those working within longer-45- or 90-day-time limits inasmuch as those in longer-term treatment have an opportunity to seek more gradual change. Contrary to expectation, however, comparison of the total number of items or comparisons of the number of individual classes of items yielded no sigfinicant differences. Therefore it must be concluded that the expectation of less as opposed to more treatment time does not affect the character of initial intrafamilial behavior change sought by therapists or clients.

Contrary to the fact that treatment contents are not significantly affected by expected treatment duration, the amount of time which therapists and clients are willing to wait before attempting to rectify problematic contracts is clearly under the influence of actual time in treatment. Table 2 shows that when treatment was limited to 2 weeks, contracts were revised within that limit, while those with more generous time limits waited longer to undertake contract revision. In keeping with this, each time contracts were subsequently revised, those working within more lenient time limits (90 days) were willing to take more time before contract revision than those with more severe ( 45 days) time limits.

\section{THERAPIST INFLUENCE UPON CONTRACT PROVISIONS AND TREAT- MENT OUTCOME}

If neither time constraint nor the nature of the contract appears significantly to influence intervention outcome, it is necessary to look elsewhere to explain the observed variance in outcome. Among other possible explanations are the effects of differences in therapist background or skill on the processes of assessment and service delivery, and the influence of the intervention technology, such as the techniques used to enhance communication within the family. The role of therapist-related factors will alone be considered here: communication change techniques and their effects are reserved for discussion in a subsequent paper.

In all, two male and eight female therapists conducted the treatment of the 79 clients in this phase of the research. Five were social work students, one was a fourth-year medical student, and four were professional social workers with from 1 to $6 \mathrm{yr}$ of experience. Each was assigned a different number of clients commensurate with his or her available time for the project and his involvement with other facets of the research.

The first variable to be considered is the role of therapist differences in determining the content of family contracts. If the differences between therapists have a negligible effect upon their efforts with clients, there should be no significant differences between the provisions of 
TABLE 2. INTERVAL IN WEEKS BETWEEN CONTRACT REVISIONS IN THREE TIME-CONSTRAINED INTREVENTION CONDITIONS

\begin{tabular}{|c|c|c|c|}
\hline Contract revision & \multicolumn{3}{|c|}{ Treatment conditions } \\
\hline $\begin{array}{l}\text { One contract only } \\
\text { Number }\end{array}$ & 18 & 8 & 10 \\
\hline \multicolumn{4}{|l|}{ First revision } \\
\hline $\begin{array}{l}\text { Mean } \\
\text { Range } \\
\text { Number }\end{array}$ & $\begin{array}{l}1.9 \\
1-3 \\
8\end{array}$ & $\begin{array}{l}4 \cdot 1 \\
1-14 \\
19\end{array}$ & $\begin{array}{l}5 \cdot 0 \\
1-10 \\
10\end{array}$ \\
\hline \multicolumn{4}{|l|}{ Second revision } \\
\hline $\begin{array}{l}\text { Mean } \\
\text { Range } \\
\text { Number }\end{array}$ & - & $\begin{array}{l}2 \cdot 8 \\
2-5 \\
7\end{array}$ & $\begin{array}{l}4 \cdot 4 \\
2-10 \\
5\end{array}$ \\
\hline \multicolumn{4}{|l|}{ Third revision } \\
\hline $\begin{array}{l}\text { Mean } \\
\text { Range } \\
\text { Number }\end{array}$ & - & $\begin{array}{l}1 \cdot 5 \\
1-2 \\
6\end{array}$ & $\begin{array}{c}4 \cdot 0 \\
3-5 \\
4\end{array}$ \\
\hline \multicolumn{4}{|l|}{ Fourth revision } \\
\hline $\begin{array}{l}\text { Mean } \\
\text { Range } \\
\text { Number }\end{array}$ & - & $\begin{array}{l}3 \cdot 3 \\
2-6 \\
3\end{array}$ & $\begin{array}{l}4 \cdot 4 \\
2-8 \\
3\end{array}$ \\
\hline
\end{tabular}

Table 3. Ciiaracteristics of contracts negotiated with the Clients of individual therapists

\begin{tabular}{|c|c|c|c|c|c|c|c|c|c|c|c|}
\hline Contract characte & & & & & & hera & & & & & \\
\hline \multicolumn{12}{|l|}{ Number of privileges } \\
\hline $\begin{array}{l}\text { Four or less } \\
\text { Five or more }\end{array}$ & $\begin{array}{l}1 \\
4\end{array}$ & $\begin{array}{l}2 \\
4\end{array}$ & $\begin{array}{l}3 \\
2\end{array}$ & $\begin{array}{l}3 \\
1\end{array}$ & $\begin{array}{r}10 \\
4\end{array}$ & $\begin{array}{l}1 \\
7\end{array}$ & $\begin{array}{l}8 \\
6\end{array}$ & $\begin{array}{l}6 \\
1\end{array}$ & $\begin{array}{l}2 \\
6\end{array}$ & $\begin{array}{l}3 \\
0\end{array}$ & $19 \cdot 46 \mathrm{a}$ \\
\hline \multicolumn{12}{|l|}{ Number of responsibilities } \\
\hline $\begin{array}{l}\text { Five or less } \\
\text { Six or more }\end{array}$ & $\begin{array}{l}3 \\
3\end{array}$ & $\begin{array}{l}1 \\
4\end{array}$ & $\frac{3}{2}$ & $\frac{2}{2}$ & 11 & $\begin{array}{l}2 \\
6\end{array}$ & $\begin{array}{l}8 \\
6\end{array}$ & $\begin{array}{l}6 \\
1\end{array}$ & $\frac{1}{7}$ & $\begin{array}{l}3 \\
0\end{array}$ & $1983 \mathrm{~b}$ \\
\hline \multicolumn{12}{|l|}{ Number of bonuses } \\
\hline $\begin{array}{l}\text { One or less } \\
\text { Two or more }\end{array}$ & $\frac{2}{4}$ & $\begin{array}{l}3 \\
2\end{array}$ & $\begin{array}{l}5 \\
0\end{array}$ & $\frac{2}{2}$ & 11 & $\begin{array}{l}3 \\
5\end{array}$ & $\begin{array}{r}4 \\
10\end{array}$ & $\begin{array}{l}6 \\
1\end{array}$ & $\begin{array}{l}4 \\
4\end{array}$ & $\begin{array}{l}3 \\
0\end{array}$ & $1884 a$ \\
\hline \multicolumn{12}{|l|}{ Number of sanctions } \\
\hline $\begin{array}{l}\text { None } \\
\text { One or more }\end{array}$ & $\begin{array}{l}0 \\
6\end{array}$ & $\frac{2}{3}$ & $\begin{array}{l}3 \\
2\end{array}$ & $\frac{1}{3}$ & $\begin{array}{l}6 \\
8\end{array}$ & $\begin{array}{l}5 \\
3\end{array}$ & $\begin{array}{r}4 \\
10\end{array}$ & $\begin{array}{l}6 \\
1\end{array}$ & $\begin{array}{l}0 \\
8\end{array}$ & $\begin{array}{l}3 \\
0\end{array}$ & $23 \cdot 47 \mathrm{c}$ \\
\hline \multicolumn{12}{|c|}{ Number of contracts per client } \\
\hline $\begin{array}{l}\text { One } \\
\text { Two or more }\end{array}$ & $\begin{array}{l}0 \\
6\end{array}$ & $\begin{array}{l}1 \\
4\end{array}$ & $\begin{array}{l}4 \\
1\end{array}$ & $\begin{array}{l}3 \\
1\end{array}$ & $\begin{array}{l}7 \\
7\end{array}$ & $\begin{array}{l}7 \\
1\end{array}$ & $\begin{array}{l}9 \\
5\end{array}$ & $\begin{array}{l}1 \\
6\end{array}$ & $\begin{array}{l}2 \\
6\end{array}$ & 2 & $22 \cdot 12 \mathrm{c}$ \\
\hline \multicolumn{12}{|l|}{ Direction of contract } \\
\hline $\begin{array}{l}\text { More home oriented } \\
\text { More school oriented }\end{array}$ & $\begin{array}{l}1 \\
5\end{array}$ & $\begin{array}{l}2 \\
2\end{array}$ & $\begin{array}{l}4 \\
0\end{array}$ & $\begin{array}{l}2 \\
2\end{array}$ & $\begin{array}{l}6 \\
6\end{array}$ & $\begin{array}{l}2 \\
5\end{array}$ & $\begin{array}{l}5 \\
8\end{array}$ & $\begin{array}{l}0 \\
6\end{array}$ & $\begin{array}{l}3 \\
5\end{array}$ & $\frac{1}{2}$ & 1279 \\
\hline
\end{tabular}


the contracts generated by different therapists. Contrary to this expectation, Table 3 shows that the content of contracts as measured by each type of item, and the number of contract renegotiations were all significantly affected by therapist influence. Only the home vs school balance of contracts was seemingly independent of therapist influence (though tending towards it).

In an experimental undertaking in which great care is taken to ensure uniformity of therapist activities, the finding that therapist differences are a more significant determinant of contract contents than either client characteristics or intervention structure is a cause of considerable alarm. In an effort to estimate the long-range effects of therapist differences, an analysis of covarience was conducted to measure the association between changes in client behavior along the six dimensions for which data were uniformly available for all clients. In this analysis baseline measures, such as grades for the two preceding semesters were averaged to form one covariant, the second covariant being the scores at the end of treatment. The results of this analysis are presented in Table 4, which reveals that therapist differences are not significantly related to the pattern of change on any of the six variables under consideration. Despite the absence of significant differences overall, however, it is clear that there was great therapist variability with respect to outcome on each of the parameters. For example, considering absences, the clients of Therapist B attended an average of 8.92 fewer days per quarter after treatment than before it, while those of Therapist $G$ attended an average of 5.19 more days per quarter after treatment. Again, the grades of the clients treated by Therapist B improved 2.33 points after treatment while those of clients treated by Therapist $F$ declined 1.43 points. While not statistically significant, the differences between treatment outcome for the clients of different therapists are noteworthy.

An explanation of one therapist differences eludes us. Neither the sex of the therapists nor their status as students or professionals was significantly related to outcome. Some of the differences may be due to complex multiple interaction effects, such as the skill of therapists appropriate to different clients and different interventions, but the small number of subjects does not permit statistical analysis of these interactions.

\section{DISCUSSION}

It has been shown that despite optimistic expectations that the details of behavioral contracts would be differentially associated with client outcomes, no such differences were apparent from the interventions involving our 79 families. Instead, significant differences appeared between the therapists' ideographic styles of handling of contracts. Fortunately, from the standpoint of preserving confidence in the importance of technology, none of the behavior patterns of therapists that were uninfluenced by intensive staff training was significantly related to therapeutic results. The lack of consistency in the findings does, however, require explanation.

In the simplest terms, the results of this phase of the research suggest that while the content of contracts per se may not matter, the existence of a contract may predispose family conflicts towards successful resolution. This can be gleaned from a comparison of the results of experimental families with contracts with those of the contrast-group families without contracts. There is, however, a need to explain how some Project families could show marked improvement and others a moderate amount of deterioration.

One possible explanation of the varied outcomes associated with the contracting procedure may be found in the process by which contracts are made. At the time of referral, when conflict within the family is likely to be at its most intense, the therapist enters the family deliberations with the suggestion that each person accommodate to a degree to the requests of the other in order that he may be able to enjoy the fulfillment of more of his privileges than in the recent past. The therapist makes the further 


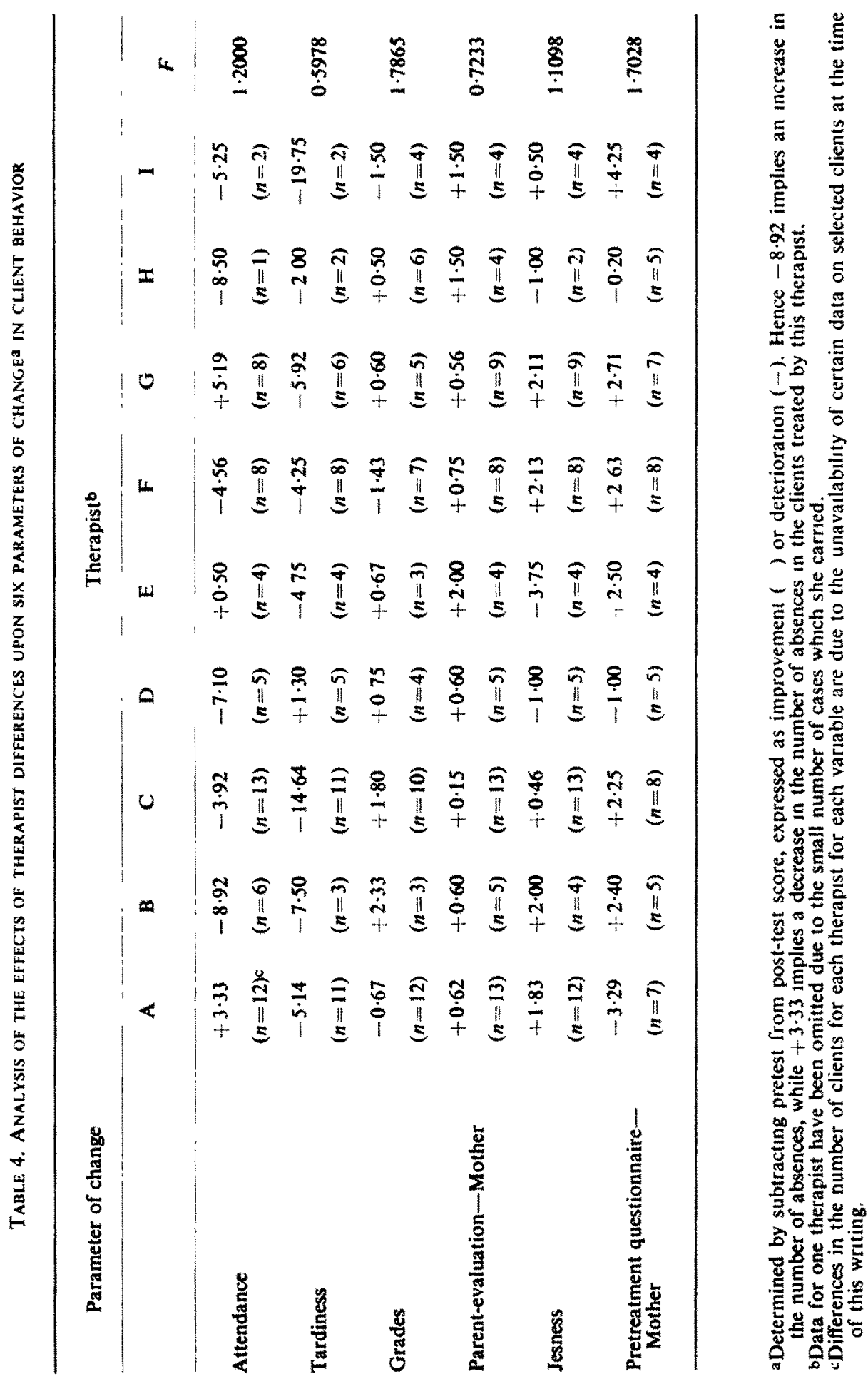


suggestion that in order to achieve this constructive change, each person must accede to the already familiar, oft-stated, oft-denied requests of the others. The therapist has to aid each person to accommodate the requests of the others so as to alter the pattern of coercive exchanges.

Three factors would be expected to influence the success of this effort. First, it would seem that families with strong histories of constructive social facilitation are more amenable to shortterm efforts to promote intrafamilial balance. Yet our data failed to reveal any facilitative characteristics of families. Second, it would seem that the immediacy of the conflict would be an important predisposing factor. Pruitt and Johnson (1970) have suggested: "A mediator's suggestions should have the greatest impact when the negotiator to whom they are presented is most in conflict between a need to make concessions and a need to appear strong ( $p$. 239)". If the initiation of service by virture of action by a social agency is problematic for either parents or youth, it can be expected that they will be more motivated to undertake an approach to problem solution which involves some costs in association with the apparent benefits. Third, and most important, it seems that the therapist's skill in structuring a climate of compromise in which no one loses face would appear to be critical with respect to clinical outcome. Stevens (1963) some time ago recognized that in labor mediation, the outcome of negotiation often depends upon a mediator's skill in assuming responsibility for shifts in positions of the bargainers rather than making it necessary for them to face their constituencies with the responsibility for compromise. In a clinical context the therapist serves a mediating role, and his skill in carrying this out may be more important than the structure of the contract.

In conclusion, it can be said that the contracting process is indeed useful; but besides attending to the details of the contracts, therapists should attend to the process through which they bring their skills to bear upon the formula- tion of contracts. The tactics of service delivery in intervention in the natural environment may rival in importance the means of intervention that they deliver

\section{REFERENCES}

CARSON R. C. (1969) Interaction concepts of peisonality, Aldine, Chicago.

JESNESS C. F. (1963) Redevelopment and revalidation of the Jesness inventory, Research Report No. 35, California Youth Authority, Sacramento, Calif

Jones E. J. and GeraRd H. B. (1967) Foundations of Social Psychology, Wiley, New York.

Patterson G. R. (1971) Behavioral intervention procedures in the classroom and in the home, Handbook of psychotherapy and behavior change (Edited by Bergin A. F. and Garfield S. L.), Wiley, New York.

Patterson G. R., McNeal S., Hawkins $N$. and PhelP R. (1967) Reprogramming the social environment, J. Child Psychol. Psychiat. 8, 181-195

Patterson G. R. and Reid J. B. (1970) Reciprocity and coercion: Two facets of social systems, Behavior Modification in Clinical Psychology (Edited by Neuringer C. and Michael. J.), Appleton-CenturyCrofts, New York.

Pruttr D. G. and Johnson D. F. (1970) Mediation as an aid to face saving in negotiation, $J$. Pers. Soc. Psychol. 14, 239-246.

SARRI R. C. and VINTER R. D. (1969) Group work for the control of behavior problems in secondary schools, Innovation in moss education (Edited by Street D.), Wiley, New York.

Stevens C. M. (1963) Strategy and Collective Bargaining Negotiation, McGraw-Hill, New York.

StUART R. B. (1971a) Behavioral contracting withın the families of delinquents, $J$. Behav. Ther. \& Exp. Psychiat. 2, 1-11.

StUART R. B. (1971b) Behavioral control of delinquency: Critique of existing programs and recommendations for innovative programming, Behavior Modification for Exceptional Children and Youth (Edited by HamerlyNK L. A. and Clark F. W.), University of Calgary Press, Calgary,

STUART R. B. (in press) The role of social work education in innovative human services, Principles and Techniques for Behavioral Engineers (Edited by CLARK F. W. and Evans $D$, R), University of Calgary Press, Calgary.

STUART R. B. and TRIPODI T. T. (in press) Experimental evaluation of three time-constrained behavioral treatments for predelinquents and delinquents, $A d$. vances in Behavior Therapy (Edited by RuBIN $\mathrm{R}$ ), Academic Press, New York.

ThARP R. G. (1971) Behavior modification as applied social psychology, Paper presented at the Saratoga Conference on Applied Behavior Modification in Human Actualization, Saratoga Springs, N.Y.

THARP R. G. and WeTzEL. R. J. (1969) Behavior Modification in the Natural Environment, Academic Press, New York.

Thibaut J. W. and Kelley H. H. (1959a) The Social Psychology of Groups, Wiley, New York.

VINTER R. D., SarRI R. C., Vorwaller D. J. and SChAFER W. E. (1966) Pupil Behavior Inventory: A manual for Administration and Scoring, Campus Publishers, Ann Arbor, Michigan. 